\title{
Electroremediation of a natural soil polluted with phenanthrene in a pilot plant
}

\author{
R. López-Vizcaíno ${ }^{\mathrm{a}}$, J. Alonso ${ }^{\mathrm{b}}$, P. Cañizares ${ }^{\mathrm{a}}$, M.J. León $^{\mathrm{b}}$, V. Navarro ${ }^{\mathrm{b}}$, M.A. Rodrigo ${ }^{\mathrm{a}}, \mathrm{C}$. \\ Sáez*a
}

${ }^{a}$ Department of Chemical Engineering, Facultad de Ciencias y Tecnologías Químicas, University of Castilla-La Mancha, Campus Universitario s/n, 13071 Ciudad Real, Spain

${ }^{b}$ Geoenvironmental Group, Civil Engineering School, University of Castilla-La Mancha, Avda. Camilo José Cela s/n, 13071 Ciudad Real, Spain

\begin{abstract}
In this work, a pilot plant with two rows of three electrodes in semipermeable electrolyte wells were used to study the electrokinetic treatment of a natural soil polluted with phenanthrene (PHE). The electrokinetic pilot plant was an open system, i.e., there was direct contact between the soil and air. To increase the solubility of phenanthrene, thereby enhancing its transport through the soil, an aqueous solution of the anionic surfactant dodecyl sulfate was used as a flushing fluid. The results show that at the pilot scale considered, gravity and evaporation fluxes are more relevant than electrokinetic fluxes. Contrary to observations at the laboratory scale, desorption of PHE promoted by electric heating appears to be a significant removal mechanism at the pilot scale. In addition, PHE is dragged by the electroosmotic flow in the cathodic wells and by electrophoresis after interaction of the surfactant with phenanthrene in the anodic wells. In spite of the long treatment time (corresponding to an energy consumption over $500 \mathrm{~kW} \mathrm{~h} \mathrm{~m}^{-3}$ ), the average removal attained was only $25 \%$.
\end{abstract}

Keywords: phenanthrene, surfactant, electroremediation, natural soil, pilot plant *Corresponding author: cristina.saez@uclm.es

1. Tel.: +34 902204100 ext. 6708 ; fax: +34 926295256 . 


\section{INTRODUCTION.}

Societal non-sustainable development has resulted in the release of a great variety of organic pollutants into soil and groundwater. The persistence of organic compounds in soil produces a complex impact that depends on numerous factors, including the physicochemical and biological properties of the pollutants, geological and chemical characteristics of the soil, the amount of soil contaminated and the quantity of pollutants. Some organic pollutants degrade in situ by indigenous microorganisms. The low solubility of other organics hinders their accessibility to microorganisms, preventing bio-degradation. A well-known group of this latter category of pollutants is the polycyclic aromatic hydrocarbons (PAHs), substances that are generally composed of non-polar molecules formed by two or more benzene rings [1]. PAHs are classified as hydrophobic organic compounds (HOC) that are highly carcinogenic, mutagenic and teratogenic [2,3]. Moreover, they are persistent in soils and sediments because of properties such as low volatility, low water solubility and low biodegradability. These characteristics inhibit their efficient removal from soil [4].

Recently, a wide variety of remediation technologies have been developed to address PAH soil pollution [5,6]. Among them, it is important to highlight the electrokinetic techniques, which are the result of different processes that occur in soil when a DC electric potential is applied through a group of electrodes located in the soil [7-10]. This flushing fluid-assisted technology has been particularly recommended for the treatment of low-permeability soil polluted with ionic and water-soluble compounds [11-12]. This technique can also be applied to the removal of hydrophobic compounds, although in this case, the non-polar character and slow desorption rates of the PAHs require the addition of special flushing fluids to increase the polarity of the pollutants, thus 
increasing their solubility in water. The special flushing fluids are usually solutions of surfactants and cosolvents [13], and they are able to improve the mass transfer of HOCs from the soil into the aqueous phase by decreasing the interfacial tension and by accumulating HOCs in the surfactant micelles [13-19]. Moreover, the addition of flushing fluids guarantees hydraulic saturation, enhances the conductivity of the soil and helps to maintain the ionic circuit in the soil.

In recent years, several works have focused on this topic. Most of them were performed at the laboratory scale [13-19], and typically, the soil electroremediation reactor consisted of a small hermetic column of less than $1 \mathrm{dm}^{3}$, in which kaolin (or other clay or lime, not natural soil) was used as a model for low-permeability soil [13]. These studies have contributed to increase knowledge about the fundamentals of electrokinetic processes. However, the extrapolation of these results to an actual application without the appropriate scale-up would be risky, according to the results shown in the few works that assess the treatment of natural soil matrixes [2,20-22].

There is a plethora of factors that can influence the efficiency of the soil flushing electroremediation process, such as electrode material, electrode location, composition and flux of flushing fluids, electric field and operation time. Although the well-known iron sacrifice electrode is proposed in some applications, ideally, electrodes should be inert materials, such as platinum, silver, gold or graphite, to prevent the development of side reactions. Among these inert materials, and taking into account economic considerations, graphite is the most commonly used in practical applications [9], in spite of the well-known poor electrochemical stability for the large cell potentials applied in electrokinetic soil remediation processes $\left(0.5-2.0 \mathrm{~V} \mathrm{~cm}^{-1}\right)$. 
With respect to the distribution of electrodes and the placement in the soil, there is great controversy. In some works, the use of electrodes in direct contact with the soil to promote the electroosmotic flux is proposed, although the electrical resistance can be high [23]. Another possibility is the insertion of the electrodes in electrolyte wells [24]. This latter option also facilitates the injection of flushing fluids. Although there are various possibilities, the use of wells containing a single cylindrical electrode appears to be the best choice. Regardless of the location of the electrodes, there are different electrode configurations, such as rows of facing electrodes and/or surrounding anodes with cathodes (or vice versa), with advantages in particular cases depending on the distribution of pollutants in the soil to be treated.

In this context, the goal of this work is to study the electrokinetic treatment of a natural soil polluted with phenanthrene (500 mg PHE kg${ }^{-1}$ soil). The electrodes were positioned into semipermeable electrolyte wells with a linear distribution (two rows of three facing electrodes). Both electrolyte wells and the soil were in direct contact with the atmosphere because the electrokinetic pilot plant was an open system. To increase the solubility of phenanthrene and thus to enhance its transport through the soil, aqueous solutions of the anionic surfactant dodecyl sulfate $\left(10 \mathrm{~g} \mathrm{dm}^{-3}\right)$ were used as a flushing fluid.

\section{MATERIALS AND METHODS.}

\subsection{Materials.}

Soil from a quarry located in Toledo (Spain) was used in this study. This soil is characterized by its inertness, low hydraulic conductivity and lack of organic content. 
The mineralogical composition and the parameters used to classify this soil by the Unified Soil Classification System (USCS) are listed in Table 1.

Phenanthrene (97\%) was selected as a model HOC. An anionic surfactant, sodium dodecyl sulfate (SDS), was used as the flushing fluid $\left(10 \mathrm{~g} \mathrm{l}^{-1}\right)$. Their properties are listed in Table 2.

\subsection{Preparation of the polluted soil}

The process of the preparation of the soil is important because of the complexity of natural soil. The process was divided into different stages: 1) positioning of three layers of gravel with different granularity for mechanical and drain support; 2) pollution of the soil with a phenanthrene/acetone solution and aeration of the spiked soil to promote evaporation of the acetone, as described in the literature [25-27]; 3) moistening the soil to $20 \%$ (a value fixed by the Proctor compaction study); 4) compaction of the soil in the electrokinetic reactor by compacting layers of a fixed height $(5 \mathrm{~cm})$ until achieving a density typical for natural soil (approximately $1.4 \mathrm{~g} \mathrm{~cm}^{-3}$ ).

\subsection{Experimental setup.}

The electrokinetic experiments were conducted in an electrokinetic remediation plant consisting of an electrokinetic reactor, a power source and tanks of electrolyte and surfactant. The reactor was a methacrylate prism with a soil capacity of $175 \times 10^{3} \mathrm{~cm}^{3}$ (LWH: 70x50x50 $\mathrm{cm}^{3}$ ). The electrodes used for both the anodes and the cathodes were graphite rods with dimensions $1 \times 1 \times 10 \mathrm{~cm}^{3}$, positioned in semipermeable electrolyte wells, using an electrode configuration of rows facing the electrolyte wells, as described elsewhere $[28,29]$. The cathodic wells are connected to $100 \mathrm{~cm}^{3}$ sewers to accumulate 
the fluid transported through the soil and facilitate sampling. The reactor is designed to separate and collect the fluids through an outlet situated on the side wall of the reactor. Figure 1 shows a schematic of the electrokinetic remediation plant.

To monitor the flux of water and the temperature evolution during the experiment, tensiometers and thermocouples were inserted into the soil. Figure 2 shows a diagram of the instrumentation.

\subsection{Experimental procedure.}

Once the plant was completely instrumented, the procedure began with the filling of the electrolyte (catholyte and anolyte were composed of water with the compositions listed in Table 3). The level of the electrolyte wells were controlled by a level control system connected to the feed tank to adjust the volume of added water or fluids to the soil. The surfactant was injected manually in intermediate wells. The test started when the power source, a 400 SM-8-AR ELEKTRONIKA DELTA BV, was turned on, applying a constant voltage gradient of $1 \mathrm{VDC} \mathrm{cm}^{-1}$.

During the experiments, the $\mathrm{pH}$, the conductivity, the surfactant concentration and the PHE concentration of the hydraulic fluids were monitored. For the monitoring, anolyte sampling was conducted manually and catholyte sampling was conducted by pumping the water accumulated in the cathodic containers. Gravity fluid is continuously drained through an outlet situated at the bottom of the reactor. The phenanthrene and surfactant concentrations, the moisture, the temperature, the $\mathrm{pH}$ and the conductivity measurements in the soil enabled the determination of the variable profiles from the anode to the cathode. 


\subsection{Analyses.}

The surfactant concentration was evaluated by monitoring the chemical oxygen demand using a HACH DR2000 analyzer [30]. The phenanthrene concentration was determined by UV-visible spectrometry (Shimadzu UV-1603). The characteristic absorbance peaks of phenanthrene in the UV-visible spectrum appeared at 346, 338 and $330 \mathrm{~nm}$. The absorbance at these three wavelengths was used to quantify the phenanthrene in the electrolyte and in the soil by the experimental procedure described in the literature [31].

\subsection{Energy consumption.}

The energy supplied is calculated using equation 1, where $\mathrm{I}$ is the electric current, $\mathrm{E}$ is the applied electric potential and $\mathrm{V}_{\text {soil }}$ is the volume of the treated soil.

$$
\text { Energy _ consumption }=\int \frac{\mathrm{I} \cdot \mathrm{E}}{\mathrm{V}_{\text {soil }}} \cdot \mathrm{dt}
$$

\section{RESULTS AND DISCUSSION.}

Figure 3 shows the time history of the resulting current density and of the energy consumption when a constant voltage gradient of $1 \mathrm{VDC} \mathrm{cm}^{-1}$ was applied between the two electrode rows of the pilot system (the row of three anodic wells and the row of three cathodic wells, according to Figure 1). This electric field is inside the range typically applied in electrokinetic soil flushing processes $\left(0.5\right.$ to $\left.2.0 \mathrm{VDC} \mathrm{cm}^{-1}\right)$ and corresponds to $50 \mathrm{~V}$ of cell potential in the pilot plant. 
The data show that the electric current density increases to a value of approximately 4.5 A $\mathrm{m}^{-2}$ after 150 hours of operation. Then, the current density begins to descend until it stabilizes at values near $2 \mathrm{~A} \mathrm{~m}^{-2}$. Steady state is reached after $1500 \mathrm{~h}$ of operation. The current is related to the rate of the electrode processes and also to the rate of the transport of ionic species in the soil. The higher the current, the faster are the electrochemical and the electrokinetic processes in the soil. In an electrochemically assisted soil remediation process, current value depends strongly on the resistance of the soil, which is a function of the moisture, the salt concentration, the temperature, etc. As a result, the increase and decrease in current is related to the processes occurring in the soil, as will be discussed below, in particular the $\mathrm{pH}$ and the moisture. Moreover, an important practical observation is the degradation of the graphite anodes from the high cell voltages that leads to the release of new species from the graphite degradation.

With respect to the energy consumption, four months of operation of the pilot plant using an electric field of $1 \mathrm{VDC} \mathrm{\textrm {cm } ^ { - 1 }}$ seems to be a long period for the decontamination of the soil. However, as shown in Figure 3, the specific energy applied to the soil during this period was $540 \mathrm{kWh} \mathrm{m}^{-3}$ (which, in terms of applied charge, corresponds to 10.8 $\mathrm{kAh} \mathrm{m}^{-3}$ ). According to EPA, energy consumptions of more than $500 \mathrm{kWh} \mathrm{m}^{-3}$ should be applied to remediate soil polluted with metals [32]. The remediation assessed in this work is not a simple electromigration process but a more complex flushing fluidassisted electroremediation process. This means that despite the long treatment time, this study was not aimed at the total removal of pollutant but rather an adequate progression in the treatment to determine the controlling mechanisms in the remediation of the soil. 
From the dynamic point of view, the hydraulic fluxes reach steady state after $1500 \mathrm{~h}$ of operation, as previously illustrated by the time history of the current intensity. Figure 4 shows the changes in the hydraulic fluxes (inlet and outlet) in the system. In the pilot system, a flushing fluid consisting of tap water was continuously added to the anodic wells to maintain the electrolyte level in the well. A different flushing fluid consisting of a surfactant solution (10 $\mathrm{g} \mathrm{dm}^{-3}$ of SDS) was added to the flushing fluid-injection wells. Initially, the unsaturated soil shows a tendency to retain water, and during the first stages, the soil moisture increased from 20 to $24 \%$. This finding explains the higher hydraulic fluxes required during the start-up of the treatment, as well as the need to add water to the cathodic wells to maintain a fixed electrolyte level in the initial stages. After $1500 \mathrm{~h}$, the fluxes stabilize at approximately 1.25 and $0.021 \mathrm{~cm}^{3} \mathrm{~cm}^{-2} \mathrm{~d}^{-1}$ in the anodic and the flushing fluid-injection wells, respectively. During operation, the electroosmotic flux produces an accumulation of water in the drain tanks placed next to the cathodic wells. From this point, catholyte is pumped and analyzed. The stationary outflux in the cathodic wells was $0.40 \mathrm{~cm}^{3} \mathrm{~cm}^{-2} \mathrm{~d}^{-1}$. A manual sampling of the anolyte is conducted $\left(0.08 \mathrm{~cm}^{3} \mathrm{~cm}^{-2} \mathrm{~d}^{-1}\right)$. Another important observation is the appearance of a hydraulic flux produced by gravity after 1200 hours of processing. This hydraulic flux $\left(0.05 \mathrm{~cm}^{3} \mathrm{~cm}^{-2} \mathrm{~d}^{-1}\right)$ is important because it does not occur in the smaller scale experimental setups described in the literature [32-35], and as shown by the data, it is not negligible in spite of the low permeability of the soil (approximately $10^{-8} \mathrm{~m} \mathrm{~s}^{-1}$ ). This means that the design of the pilot plant is a more realistic representation of fullscale soil treatment.

With respect to this design, another important difference from conventional setups for the assessment of electrokinetic soil remediation is that the pilot plant is open to 
atmosphere, i.e., there is direct contact between the soil and air. Therefore, water losses by evaporation may be important. The rate of water evaporation calculated by a water mass balance is $0.78 \mathrm{~cm}^{3} \mathrm{~cm}^{-2} \mathrm{~d}^{-1}$, higher than the water loss through electroosmotic transport. This process may be influenced by the gradual heating of the soil during the remediation. Figure 5 shows the temperature maps of the soil at different operating times. The data show that soil temperature increases from an initial average temperature of $19{ }^{\circ} \mathrm{C}$ to a final $30^{\circ} \mathrm{C}$. This heating may be related to the ohmic decrease generated in the system by the electrical resistance of electrodes, the conductive elements, and of the soil itself. All of the power supplied to the system does not lead to the generation of an electric current, but a significant fraction is dissipated as heat (8), particularly in areas near the electrodes, as shown in Figure 5. There is a cluster of lower temperatures near the electrode wells, which can be explained by the cooling effect of the addition of water and flushing fluids.

There is also a formation of carbonate deposits on the cathode surface and on the cathodic wells during the electroremediation process. Their formation is from the combination of the hydroxyl ions and the bicarbonate present in the soil (eq. 2) as follows:

$$
\mathrm{HCO}_{3}^{-}+\mathrm{OH}^{-} \rightarrow \mathrm{CO}_{3}^{2-}
$$

Carbonate deposits have high electrical resistance, and their formation thus increases the overall resistance of the system [36], although it does not appear to increase the temperature of the soil significantly. The presence of carbonates limits the development 
of the electrokinetic processes involved in the treatment and can also help to explain the tendency observed in the current density (Figure 3).

Figure 6a shows the variation of the $\mathrm{pH}$ in the cathodic and anodic wells during the process. The results show that initially there is an abrupt change in the electrolyte well $\mathrm{pH}$ from the initial value $(\mathrm{pH}$ 6) to $\mathrm{pH} 2$ and $\mathrm{pH} 12$ in the anodic and cathodic wells, respectively. These $\mathrm{pH}$ changes are related to the electrolysis of water (eqs. 3 and 4), which leads to the production of protons inside the anodic wells and hydroxyl anions in the cathodic wells as follows:

$$
\begin{aligned}
& \mathrm{H}_{2} \mathrm{O}-2 \mathrm{e}-\rightarrow 1 / 2 \mathrm{O}_{2}+2 \mathrm{H}^{+} \\
& \mathrm{H}_{2} \mathrm{O}+\mathrm{e}_{-} \rightarrow 1 / 2 \mathrm{H}_{2}+\mathrm{OH}^{-}
\end{aligned}
$$

Then, after the initial rapid change, the $\mathrm{pH}$ of the catholyte decreases to a nearly constant value. This $\mathrm{pH}$ decrease may be caused by other electrochemical reactions that occur on the cathode surface or by the consumption of hydroxyl ions in other processes, such as precipitation and/or complexation of salts or metals.

The electrolysis and the resulting $\mathrm{pH}$ profile can also explain the trend observed in the conductivity. Figure $6 \mathrm{~b}$ shows the variation of the conductivity of the catholyte, the anolyte and the gravity fluid during the process. The data show that the formation of ions $(\mathrm{H}+, \mathrm{OH}-)$ inside the electrolyte wells produces an abrupt increase in the conductivity of both electrolyte wells. However, the conductivity of the anolyte is nearly constant at approximately $15 \mathrm{mS} \mathrm{cm}^{-1}$, while the conductivity of the catholyte decreases continuously to $5 \mathrm{mS} \mathrm{cm} \mathrm{cm}^{-1}$ after $1200 \mathrm{~h}$ of processing. This trend indicates a reduction in ionic concentration in the cathodic wells, which may be produced either by 
a consumption of hydroxyl ions in side processes (formation of carbonates) or by the electrokinetic movement of ionic species toward the catholyte being developed to a lesser extent. Both assumptions are consistent with the descending trend observed in the current density (Figure 3) and the $\mathrm{pH}$ (Figure 6a). Moreover, the $\mathrm{pH}$ and the conductivity of the gravity fluid do not appear to change significantly, and flat profiles (approximately neutral $\mathrm{pH}$ and $3 \mathrm{mS} \mathrm{cm}^{-1}$ ) are achieved with time.

Both protons and hydroxyl ions move to the electrodes of opposite sign by ionic electromigration. Consequently, the $\mathrm{pH}$ of the soil experiences changes from the movement of the acidic front towards the cathode, and of the basic front towards the anode. Figure 7 shows 3-D pH maps (the z-axis is divided into three soil layers of $8 \mathrm{~cm}$ thick each, i.e., surface, middle and bottom layers) after $2800 \mathrm{~h}$ of processing. Ideally, the $\mathrm{pH}$ would be neutral in an intermediate area between the cathodic and the anodic wells. However, the data in this figure show that the neutral zone is closer to the anodic wells, indicating that the basic front moves faster than the acid front. This trend is the opposite of the trend observed in synthetic soils studied in the literature [37-40], where the neutral zone appears to be closer to the cathodic area. This phenomenon may be related to the physicochemical processes involving protons and hydroxyl ions, such as the dissolution of precipitates in the case of protons, the precipitation of metals in the case of the hydroxyl ions and ion exchange for both.

Based on the low solubility in water of phenanthrene (PHE) as well as its apolarity, a flushing fluid consisting of a surfactant solution was added to the flushing fluidinjection wells to enhance the solubility of PHE by breaking up the HOCs into the hydrophobic cores of the surfactant micelles. The surfactant used in this study (SDS) 
was previously selected in a soil washing assessment study [41]. It has negatively charged functional groups and thus can be transported by electromigration to anodic wells and by electroosmosis to cathodic wells. The accumulation of surfactant in both types of wells suggests that the surfactant should be added to non-electrolytic wells positioned inside the zone enclosed by the two electrode rows, then transported by the electroosmotic flux and by migration. In addition, this approach ensures total disappearance of the reactant from the treated soil once it has been used to mobilize the organic pollutants. Figure 8 shows the time history of the quantity of surfactant accumulated in the anolyte, the catholyte and the gravity fluid. The data show that the surfactant moves primarily to the anodic wells, reaching approximately $5500 \mathrm{mg}$ of surfactant after $1100 \mathrm{~h}$. The amount of surfactant in the cathodic wells is significantly lower; no surfactant was detected in the gravity fluid. In general, the amount of surfactant accumulated in the output fluxes is low compared to the total amount of surfactant introduced into the system (approximately 40,000 mg), which suggests that most of surfactant has not yet reached the electrolyte wells and that it accumulates in the soil. An analysis of the surfactant concentration in the soil after the electroremediation process shows that the higher concentration of surfactant $\left(600 \mathrm{mg}\right.$ surfactant $\mathrm{kg}^{-1}$ of soil) is obtained in the region close to the flushing fluid-injection wells. In addition, the formation of a gelatinous substance was noticed in the injection wells. The appearance of this substance can be related to water losses by evaporation that concentrates the surfactant solution inside the injection wells.

Figure 9 shows the amount of PHE accumulated in the output fluxes of the system. The data show that phenanthrene is primarily accumulated in the cathodic wells, and the amount of PHE accumulated in the gravity flux and in the anolyte is much lower. 
However, the presence of PHE in gravity flux can involve a very significant contamination risk. Thus, when soil pollution event occurs it is recommended a rapid act to remediate the site and to prevent further spread of pollution to groundwater.

The addition of the surfactant allows the PHE to move to the anodic wells by electrophoretic transport of the micelles formed between the contaminant and the added anionic surfactant and to the cathodic wells by electroosmotic transport. However, these results show that the removal of PHE appears to be primarily dragging with electroosmotic flow to the cathodic wells and that, in spite of the high surfactant accumulation in anodic wells, the addition of the surfactant does not seem to allow the massive mobilization of PHE to the anodic wells by electrophoretic transport. This low accumulation of PHE in anodic wells may be related to the high surfactant concentration used that may cause the retention of PHE in soil, and consequently may complicate its mobilization to anodic wells. Regarding the PHE accumulation trend in cathodic wells, it is observed that initially the rate of accumulation of PHE in cathodic wells is low $\left(0.066 \mathrm{mg} \mathrm{PHE} \mathrm{h}^{-1}\right)$ but it increases abruptly after $1200 \mathrm{~h}$ of processing till $0.35 \mathrm{mg} \mathrm{PHE} \mathrm{h}^{-1}$. It is important to point out that this trend is related to the changes observed in catholyte flux (Figure 4b). The abrupt increase observed in catholyte flux after $1100 \mathrm{~h}$ of processing corresponds to the increment of the shape of the PHEcumulative curve.

Figure 10 shows the 3-D maps of phenanthrene concentration in soil (z-axis divided into three soil layers of $8 \mathrm{~cm}$ thick (surface, middle and bottom layers) after $2800 \mathrm{~h}$ of processing . The data show that the final distribution of PHE in the soil is not uniform. As discussed previously, during the electroremediation process, a gradual heating of the soil favors the volatilization of PHE [42]. Most PHE is removed from the surface layer, 
whereas in the bottom layer, the percentage of PHE removed is very low, except in the zone close to the cathodic wells. The higher efficiency observed in the three soil layers in the zone close to the cathodic wells can be related to the increase of the temperature in this zone from the intense electric heating, combined with the lack of the cooling effect provided by the addition of fluids. The average removal attained is $25 \%$, and the PHE flux removed by volatilization (estimated by mass balance) is $350 \mathrm{mg} \mathrm{PHE} \mathrm{m}^{-2} \mathrm{~d}^{-1}$. The volatilization of PHE can imply effects on the human health and on the environment and thus, it must be evaluated the importance of PHE desorption in the risk assessment for human health.

These results indicate that the remediation process is slow and that to attain complete remediation of the soil, the energy applied must be higher than $540 \mathrm{~kW} \mathrm{~h} \mathrm{~m}^{-3}$. Nevertheless, this study discovered the significant contribution of non-electrokinetic processes in the removal of PHE. Thus, in addition to the PHE dragged with electroosmotic flux in the cathodic wells and with electrophoretic flux in the anodic wells, desorption of PHE also plays an important role at the pilot scale.

\section{Conclusions}

The following conclusions result from this work:

- In the electroremediation of soil at the pilot scale, there are many processes controlled by non-electrochemical mechanisms that are important (and that are not observed on the laboratory scale). Even in the case of low-permeability soil, gravity and evaporation fluxes are more relevant than electrokinetic fluxes.

- The primary mechanisms involved in the removal of PHE are and desorption produced by electric heating of the soil, dragging with electroosmotic flow in the 
cathodic wells and electrophoresis after interaction of surfactant with phenanthrene in the anodic wells.

- The decontamination of soils by a flushing fluid-assisted electroremediation process is a feasible process, even though it is slow, requiring large operation time and energy consumption

- The presence of PHE in gravity and evaporation fluxes may imply effects on the human health and on the environment.

\section{ACKNOWLEDGEMENTS}

This work was supported by the MCT (Ministerio de Ciencia y Tecnología, Spain) and by the EU (European Union) through project CTM2010-18833/TECNO and the INNOCAMPUS Program of the University of Castilla La Mancha. 


\section{References.}

[1] D.W. Connell, Basic Concepts of environmental chemistry, Lewis Publishers, New York, 1997.

[2] K.R. Reddy, P.R. Ala, S. Sharma, S.N. Kumar, Enhanced electrokinetic remediation of contaminated manufactured gas plant soil, Eng. Geol. 85 (2006) 132146.

[3] P-J. Tsai, H-Y. Shieh, W-J. Lee, S-O. Lai, Health-risk assessment for workers exposed to polycyclic aromatic hydrocarbons (PAHs) in a carbon black manufacturing industry, Sci Total Environ. 278 (2001) 1-3.

[4] A.W. Hatheway, Geoenvironmental protocol for site and waste characterization of former manufactured gas plants; worldwide remediation challenges in semi volatile organic wastes, Eng.Geol. 64 (2002) 317-338.

[5] K.R. Reddy, Technical challenges to in-situ remediation of polluted sites, Geotech. Geol. Eng. 28 (2010) 211-221.

[6] S. Gan, E.V. Lau, H.K. Ng, Remediation of soils contaminated with polycyclic aromatic hydrocarbons (PAHs), J. Hazard. Mater. 172 (2009) 532-549.

[7] M.M. Page, C.L. Page, A review of electroremediation of contaminated soils, J. Environ. Eng. 128 (2002) 208-219.

[8] R.E. Saichek, K.R. Reddy, Electrokinetically enhanced remediation of hydrophobic organic compounds in soils: A Review, Environ. Sci. Technol. 35 (2005) 115-192.

[9] J. Virkutyte, M. Sillanpää, P. Latostenmaa, Electrokinetic soil remediationcritical overview, Sci. Total Environ. 289 (2002) 97-121.

[10] A.N. Alshawabkeh, Electrokinetic soil remediation: Challenges and opportunities, Sep. Sci. Technol. 44 (2009) 2171-2187. 
[11] K.R. Reddy, K. Maturi, C. Cameselle, Sequential electrokinetic remediation of mixed contaminants in low permeability soils, J. Environ. Eng. 135 (2009) 989-998.

[12] A. Colacicco, G. de Gioannis, A. Muntoni, E. Pettinao, A. Polettini, R. Pomi, Enhanced electrokinetic treatment of marine sediments contaminated by heavy metals and PAHs, Chemosphere 81 (2010) 46-56.

[13] M. Pazos, E. Rosales, T. Alcántara, J. Gómez, M.A. Sanromán, Decontamination of soils containing PAHs by electroremediation: A review, J. Hazard. Mater. 177 (2010) 1-11.

[14] M.T. Alcántara, J. Gómez, M. Pazos, M.A. Sanromán, Electrokinetic remediation of PAH mixtures from kaolin, J. Hazard. Mater. 179 (2010) 1156-1160.

[15] K. Maturi, K.R. Reddy, C. Cameselle, Surfactant-enhanced electrokinetic remediation of mixed contamination in low permeability soil, Sep. Sci. Technol. 44 (2009) 2385-2409.

[16] C.N. Mulligan, R.N. Yong, B.F. Gibbs, Surfactant-enhanced remediation of contaminated soil: a review, Eng. Geol. 60 (2001) 371-380.

[17] J.N. Hahladakis, W. Calmano, E. Gidarakos, Use and comparison of the nonionic surfactants Poloxamer 407 and Nonidet P40 with HP- $\beta$-CD cyclodextrin, for the enhanced electroremediation of real contaminated sediments from PAHs, Sep. Purif. Technol. 113 (2013) 104-113.

[18] A.T. Lima, L.M. Ottosen, K. Heister, J.P.G. Loch, Assessing PAH removal from clayey soil by means of electro-osmosis and electrodialysis, Sci. Total Environ. 435 (2012) 1-6.

[19] M.T. Alcántara, J. Gómez, M. Pazos, M.A. Sanromán, Electrokinetic remediation of lead and phenanthrene polluted soils, Geoderma 173 (2012) 128-133. 
[20] A.B. Ribeiro, J.M. Rodriguez-Maroto, E.P. Mateus, H. Gomes, Removal of organic contaminants from soils by an electrokinetic process: the case of atrazine: Experimental and modeling, Chemosphere 59 (2005) 1229-1239.

[21] M.D. Garcia-Gutierrez, C. Gomez-Lahoz, J.M. Rodriguez-Maroto, C. VeredaAlonso, F. Garcia-Herruzo, Electrokinetic remediation of a soil contaminated by the pyritic sludge spill of Aznalcollar (SW, Spain), Electrochim. Acta 52 (2007) 3372-3379. [22] A. García-Rubio, J.M. Rodriguez-Maroto, C. Gómez-Lahoz, F. García-Herruzo, C. Vereda-Alonso, Electrokinetic remediation: The use of mercury speciation for feasibility studies applied to a contaminated soil from Almadén, Electrochim. Acta 56 (2011) 9303-9310.

[23] K. Reddy, M. Donahue, R. Sasaoka, Preliminary assessment of electro-kinetic remediation of soil and sludge contaminated with mixed waste, J. Air Waste Managem. Assoc. 49 (1999) 823-830.

[24] S.S. Al-Shaharani, E.P.L. Roberts, Electrokinetic removal of caesium from kaolin. J. Hazard. Mater. 122 (2005) 91-101.

[25] J-Y. Park, H-H. Lee, S-J. Kim, Y-J. Lee, J-W. Yang, Surfactant-enhanced electrokinetic removal of phenanthrene from kaolinite, J. Hazard. Mater. 140 (2007) $230-236$.

[26] M.T. Alcántara, J. Gómez, M. Pazos, M.A. Sanromán, PAHs soil decontamination in two steps: desorption and electrochemical treatment, J. Hazard. Mater. 166 (2009) 462-468.

[27] M.T. Alcántara, J. Gómez, M. Pazos, M.A. Sanromán, Combined treatment of PAHs contaminated soils using the sequence extraction with surfactant electrochemical degradation, Chemosphere 70 (2008) 1438-1444. 
[28] R. López-Vizcaíno, C. Sáez, E. Mena, J. Villaseñor, P. Cañizares, M.A. Rodrigo, Electro-osmotic fluxes in multi-well electro-remediation processes, J. Environ. Sci. Health. Part A Toxic/Hazard. Subst. Environ. Eng. 46 (2011) 1549-1557.

[29] R. López-Vizcaíno, C. Sáez, P. Cañizares, V. Navarro, M.A. Rodrigo, Influence of the type of surfactant on the mobility of flushing fluids for electro-remediation processes, Sep. Sci. Technol. 46 (2011) 2148-2156.

[30] L.S. Clesceri, A.E. Greenberg, A.D. Eaton, M.A.H. Franson, APHA, AWWA, WPCF. Standard Methods for the Examination of Water and Wastewater, 20th Ed., American Public Health Association: Washington DC, 1989.

[31] R. López-Vizcaíno, C. Sáez, P. Cañizares, M.A. Rodrigo, The use of a combined process of surfactant-aided soil washing and coagulation for PAH-contaminated soils treatment, Sep. Purif. Technol. 88 (2012) 46-51.

[32] USAEC, In-situ electrokinetic remediation for metal contaminated soils. En: Innovative Technology Demonstration, Evaluation and Transfer Activities, FY 96 Annual Report, Report No. SFIM-AEC-ETCR-97013, United States Army Environmental Center, (1997) 87-88.

[33] P. Lu, Q. Feng, Q. Meng, T. Yuan, Electrokinetic remediation of chromiumand cadmium-contaminated soil from abandoned industrial site . Sep. Purif. Technol. 98 (2012) 216-220.

[34] L. Cang, G-P. Fan, D-M Zhou, Q-Y Wang, Enhanced-electrokinetic remediation of copper-pyrene co-contaminated soil with different oxidants and $\mathrm{pH}$ control, Chemosphere 90 (2013) 2326-2331.

[35] F. Rozas, M. Castellote, Electrokinetic remediation of dredged sediments polluted with heavy metals with different enhancing electrolytes. Electrochim. Acta 86 (2012) 102-109. 
[36] P. Cañizares, C. Sáez, E. Romero-Girón, J. García-Gómez, M.A. Rodrigo, Tratamiento de suelos mediante procesos electroquímicos. Parte 2: Tecnología. Afinidad 64 (2007) 671-680.

[37] K. Maturi, K.R. Reddy, Cosolvent-enhanced desorption and transport of heavy metals and organic contaminants in soils during electrokinetic remediation, Water Air Soil Pollut. 189 (2008) 199-211.

[38] Y-J. Lee, H. Han, S-H. Kim, J-W. Yang, Combination of electrokinetic separation and electrochemical oxidation for acid dye removal from soil, Sep. Sci. Technol. 44 (2009) 2455-2469.

[39] A.Z. Al-Hamdan, K.R. Reddy, Electrokinetic remediation modelling incorporating geochemical effects, J. Geotech. Geoenviron. Eng. 134 (2008): 91-105.

[40] J-Y. Wang, X-J. Huang, J.C.M. Kao, O. Stabnikova, Simultaneous removal of organic contaminants and heavy metals from kaolin using an upward electrokinetic soil remediation process, J. Hazard. Mater. 144 (2007) 292-299.

[41] R. López-Vizcaíno, C. Sáez, P. Cañizares, M.A. Rodrigo, The use of a combined process of surfactant-aided soil washing and coagulation for PAH-contaminated soils treatment, Sep. Purif. Technol. 88 (2012) 46-51.

[42] A.F. Wick, N.H. Haus, B.F. Sukkariyah, K.C. Haering, Remediation of PAHcontaminated soils and sediments: a literature review, Virginia Polytechnic Institute and State University. 2011. 
Table 1. Mineralogical composition and classification by USCS.

\begin{tabular}{|c|c|}
\hline Mineral & $\%$ \\
\hline Quartz & 12 \\
\hline Feldspar & 6 \\
\hline Calcite & 1 \\
\hline Kaolinite & 23 \\
\hline Glauconite & 24 \\
\hline Muscovite & 8 \\
\hline Montmorillonite & 20 \\
\hline Smectite & - \\
\hline Illite & 6 \\
\hline \multicolumn{2}{|c|}{ Parameters } \\
\hline Liquid Limit & 42 \\
\hline Plastic Limit & 24 \\
\hline Plasticity Inde & 18 \\
\hline \multicolumn{2}{|l|}{ USCS Code } \\
\hline Low $p$ & \\
\hline
\end{tabular}

Table 2. Properties of the surfactant.

\begin{tabular}{ll}
\hline Surfactant & Sodium dodecyl sulfate \\
Type & Anionic \\
Formula & $\mathrm{C}_{12} \mathrm{H}_{25} \mathrm{NaO}_{4} \mathrm{~S}$ \\
$\mathbf{M W}$ & 288.38 \\
$\mathbf{C M C} / \mathbf{~ g l}^{-1}$ & 2.3 \\
\hline
\end{tabular}

Molecular structure 


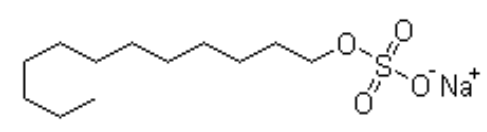

Table 3. Water composition.

\begin{tabular}{|c|c|}
\hline \multicolumn{2}{|c|}{ Parameters } \\
\hline Conductivity / $\mathrm{mS} \mathrm{cm}^{-1}$ & 0.391 \\
\hline $\mathbf{p H}$ & 7.64 \\
\hline \multicolumn{2}{|c|}{ Salts concentration / $\mathrm{mg} \mathrm{dm}^{-3}$} \\
\hline $\mathbf{C a}$ & 35.23 \\
\hline $\mathrm{Cl}^{-}$ & 57.26 \\
\hline $\mathbf{F e}$ & 0.15 \\
\hline $\mathbf{F}$ & 0.702 \\
\hline Mg & 0.011 \\
\hline Mn & 0.048 \\
\hline $\mathbf{N a}$ & 12.09 \\
\hline $\mathbf{K}$ & 11.72 \\
\hline $\mathrm{NO}_{3}^{-}$ & 6.22 \\
\hline $\mathrm{SO}_{4}^{-2}$ & 44.41 \\
\hline
\end{tabular}




\section{Figure captions.}

Figure 1. Diagram of the electrokinetic remediation plant.

Figure 2. Diagram of the instrumentation used in the electrokinetic remediation plant.

Figure 3. Time history of the electric current $(\diamond)$ and the energy supplied $(\square)$ in the electroremediation of a natural soil polluted with phenanthrene. Operating condition: Ez = $1 \mathrm{VDC} / \mathrm{cm}$, initial pollution: $500 \mathrm{mg}$ PHE kg-1 of soil, anolyte: water, catholyte: water, flushing solution: $10 \mathrm{~g}$ of anionic surfactant $\mathrm{dm}^{-3}$.

Figure 4. Time history of the hydraulic fluxes in the electroremediation of a natural soil polluted with phenanthrene. Operating condition: $\mathrm{Ez}=1 \mathrm{VDC} / \mathrm{cm}$, initial pollution: 500 mg of PHE kg-1 of soil, anolyte: water, catholyte: water, flushing solution: $10 \mathrm{~g}$ of anionic surfactant $\mathrm{dm}^{-3}$. a) Inlet fluxes: $\bullet$ Anolyte, $\triangle$ Surfactant; b) Outlet fluxes: Catholyte, $\triangle$ Gravity fluid.

Figure 5. 3-D maps of the soil temperature during the electroremediation of a natural soil polluted with phenanthrene. Operating condition: $\mathrm{Ez}=1 \mathrm{VDC} / \mathrm{cm}$, initial pollution: $500 \mathrm{mg}$ of PHE kg-1 of soil, anolyte: water, catholyte: water, flushing solution: $10 \mathrm{~g}$ of anionic surfactant $\mathrm{dm}^{-3}$. a) $100 \mathrm{~h}$, b) $1100 \mathrm{~h}$, c) $2800 \mathrm{~h}$.

Figure 6. Time history of the $\mathrm{pH}$ (a) and the conductivity (b) of the outflows for the electroremediation of a natural soil polluted with phenanthrene. Operating condition: Ez = $1 \mathrm{VDC} / \mathrm{cm}$, initial pollution: $500 \mathrm{mg}$ of PHE kg-1 of soil, anolyte: water, catholyte: water, flushing solution: $10 \mathrm{~g}$ of anionic surfactant $\mathrm{dm}^{-3} .(\diamond)$ Anolyte, $(\square)$ Catholyte and $(\triangle)$ Gravity fluid.

Figure 7. 3-D maps of the $\mathrm{pH}$ of the soil after $2800 \mathrm{~h}$ of the electroremediation process of a natural soil polluted with phenanthrene. Operating condition: $\mathrm{Ez}=1 \mathrm{VDC} / \mathrm{cm}$, initial pollution: $500 \mathrm{mg}$ of PHE kg-1 of soil, anolyte: water, catholyte: water, flushing 
solution: $10 \mathrm{~g}$ of anionic surfactant $\mathrm{dm}^{-3}$. a) surface layer, b) middle layer, c) bottom layer.

Figure 8. Time history of the surfactant fluxes accumulated in the outflows during the electroremediation of a natural soil polluted with phenanthrene. Operating condition: Ez = $1 \mathrm{VDC} / \mathrm{cm}$, initial pollution: $500 \mathrm{mg}$ of PHE kg-1 of soil, anolyte: water, catholyte: water, flushing solution: $10 \mathrm{~g}$ of anionic surfactant $\mathrm{dm}^{-3} .(\diamond)$ Anolyte, $(\square)$ Catholyte and $(\triangle)$ Gravity fluid.

Figure 9. Time history of the amount of phenanthrene (PHE) accumulated in the outflows during the electroremediation of a natural soil polluted with phenanthrene. Operating condition: $\mathrm{Ez}=1 \mathrm{VDC} / \mathrm{cm}$, initial pollution: $500 \mathrm{mg}$ of $\mathrm{PHE} \mathrm{kg}-1$ of soil, anolyte: water, catholyte: water, flushing solution: $10 \mathrm{~g}$ of anionic surfactant $\mathrm{dm}^{-3} .(\diamond)$ Anolyte, $(\square)$ Catholyte and $(\triangle)$ Gravity fluid.

Figure 10. 3-D maps of phenanthrene (PHE) in the soil after $2800 \mathrm{~h}$ of the electroremediation process of a natural soil polluted with phenanthrene. Operating condition: $\mathrm{Ez}=1 \mathrm{VDC} / \mathrm{cm}$, initial pollution: $500 \mathrm{mg}$ of PHE $\mathrm{kg}-1$ of soil, anolyte: water, catholyte: water, flushing solution: $10 \mathrm{~g}$ of anionic surfactant $\mathrm{dm}^{-3}$. a) surface layer, b) middle layer, c) bottom layer. 


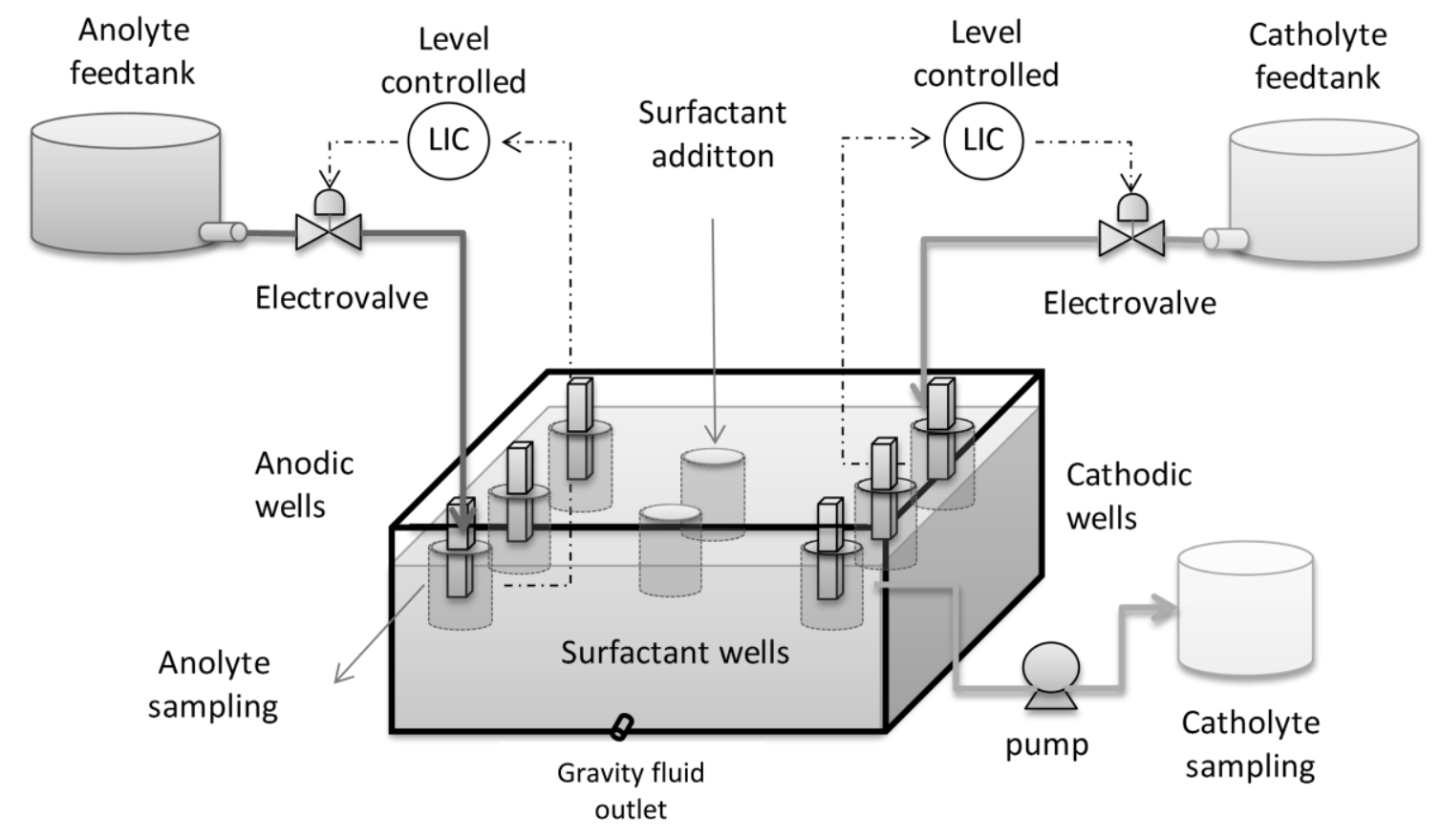

Figure 1. 
P1, P2 y and P3 Cathodic wells

P4, P5 y P6 Anodic wells

C1, C2 y C3 Cathodic sewers

PS1 y PS2 Surfactant wells

TT1-TT5 Thermocouples

O T1-T8 Tensiometers

O TC1 y TC2 Control Tensiometers

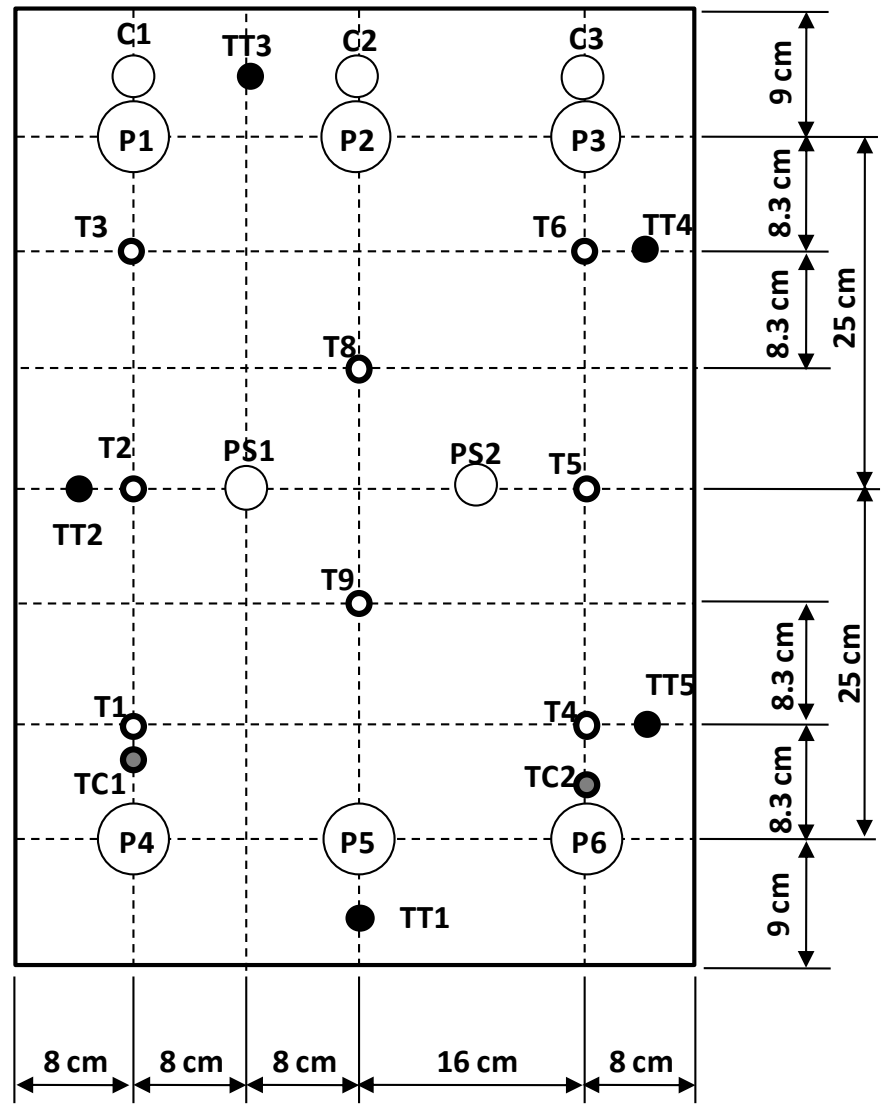

Figure 2. 


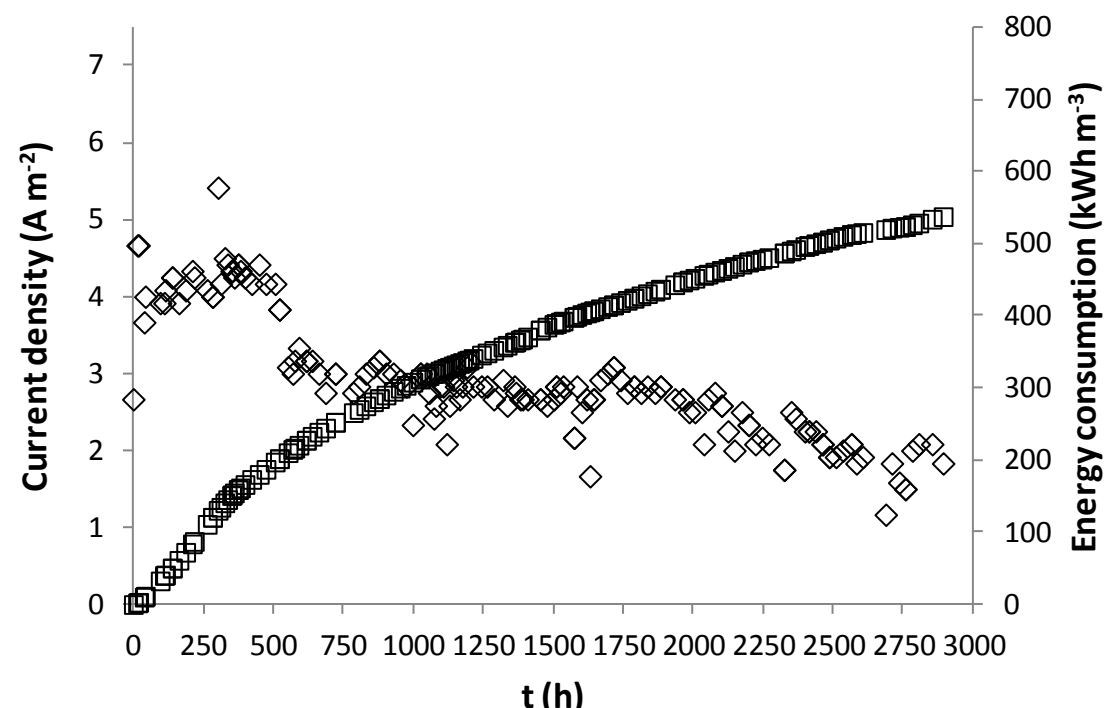

Figure 3. 

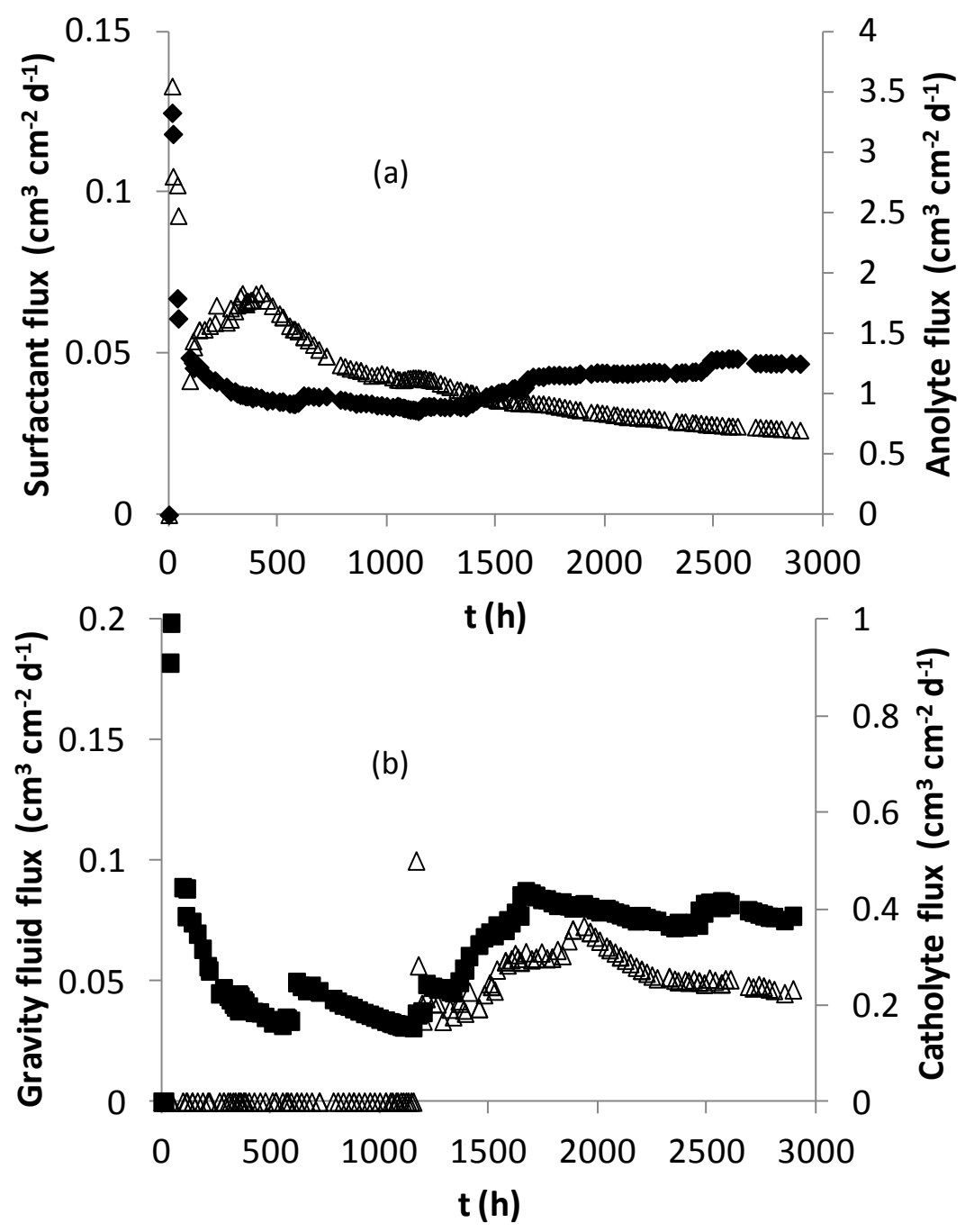

Figure 4. 

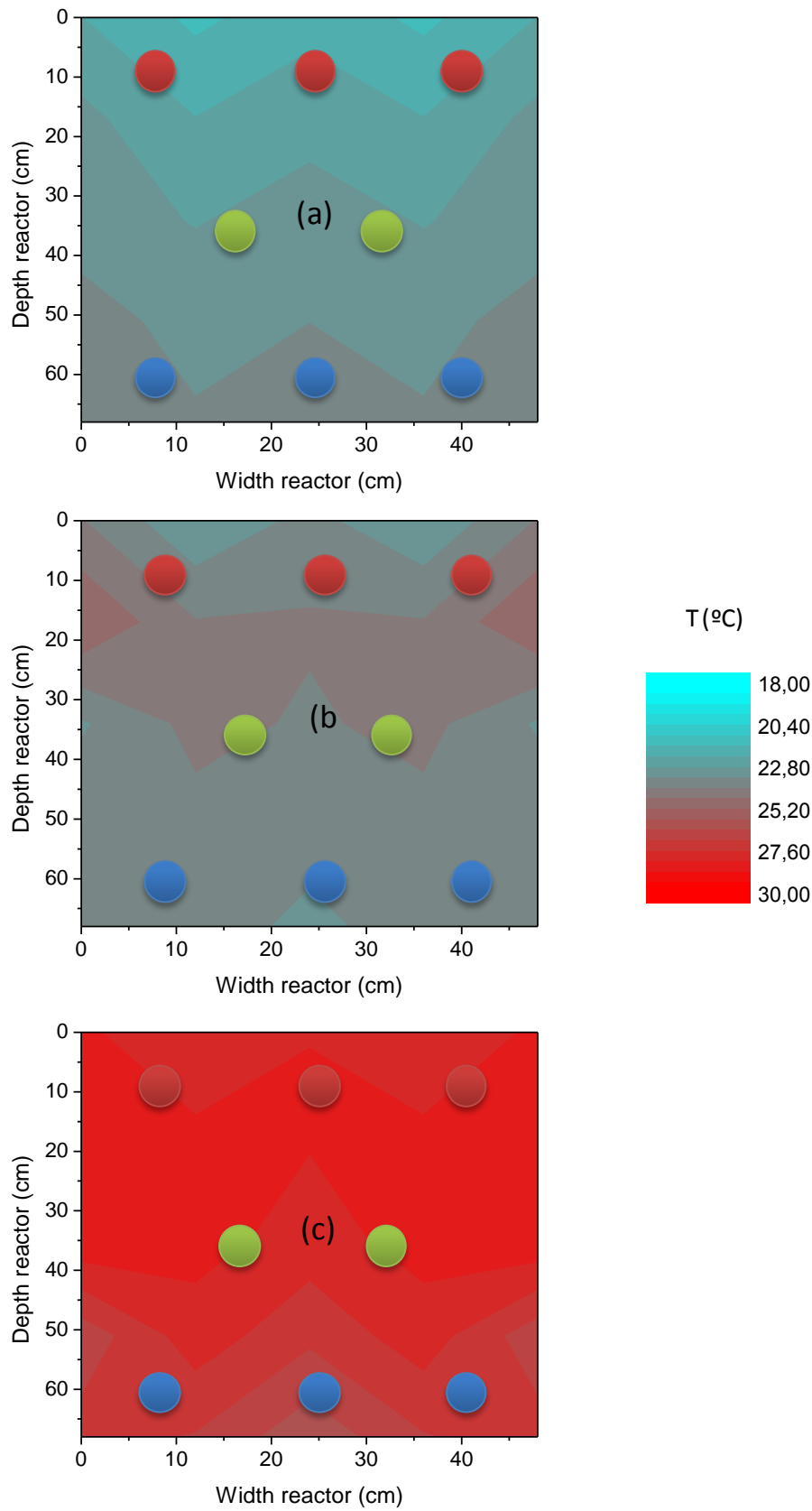

Figure 5. 


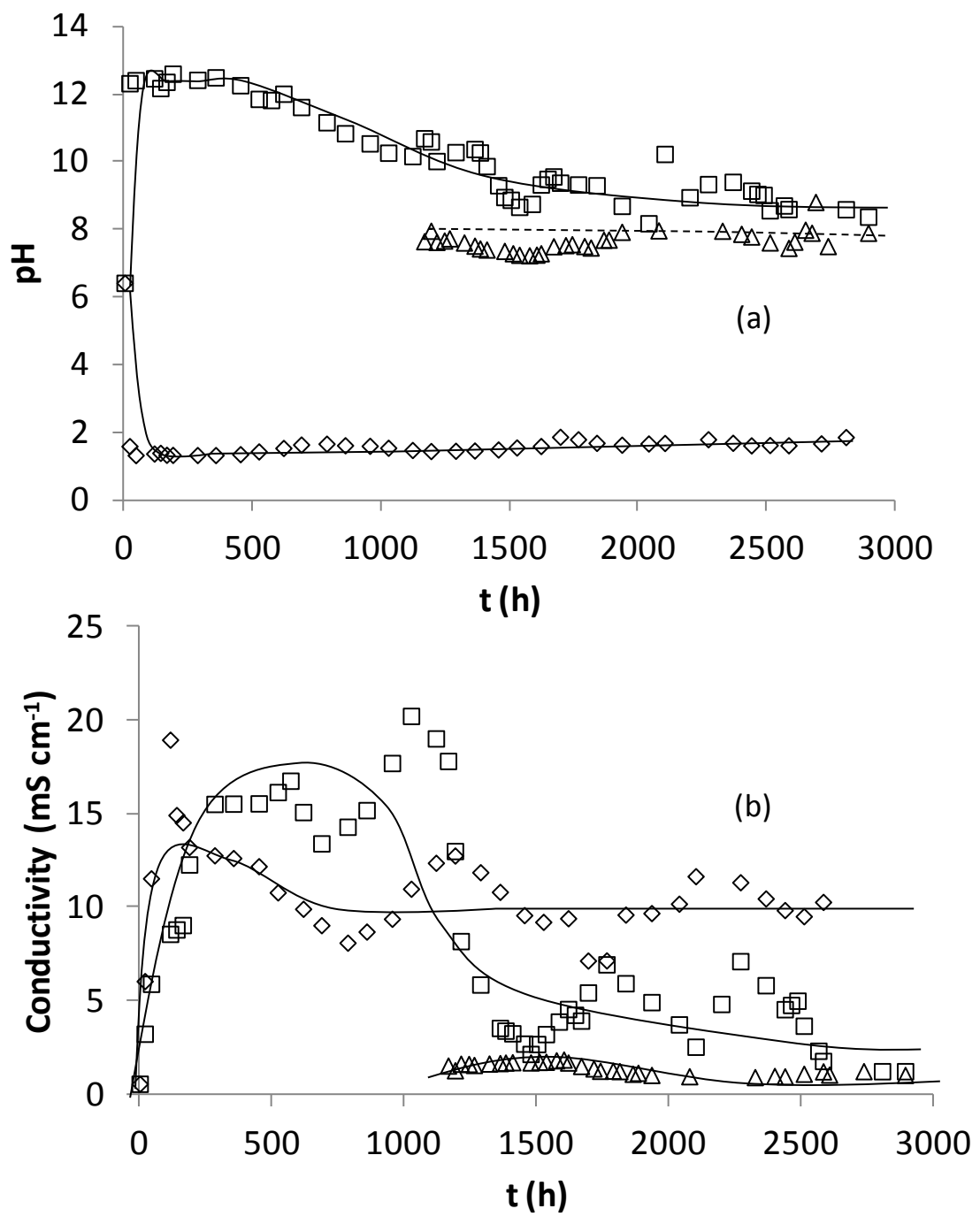

Figure 6. 

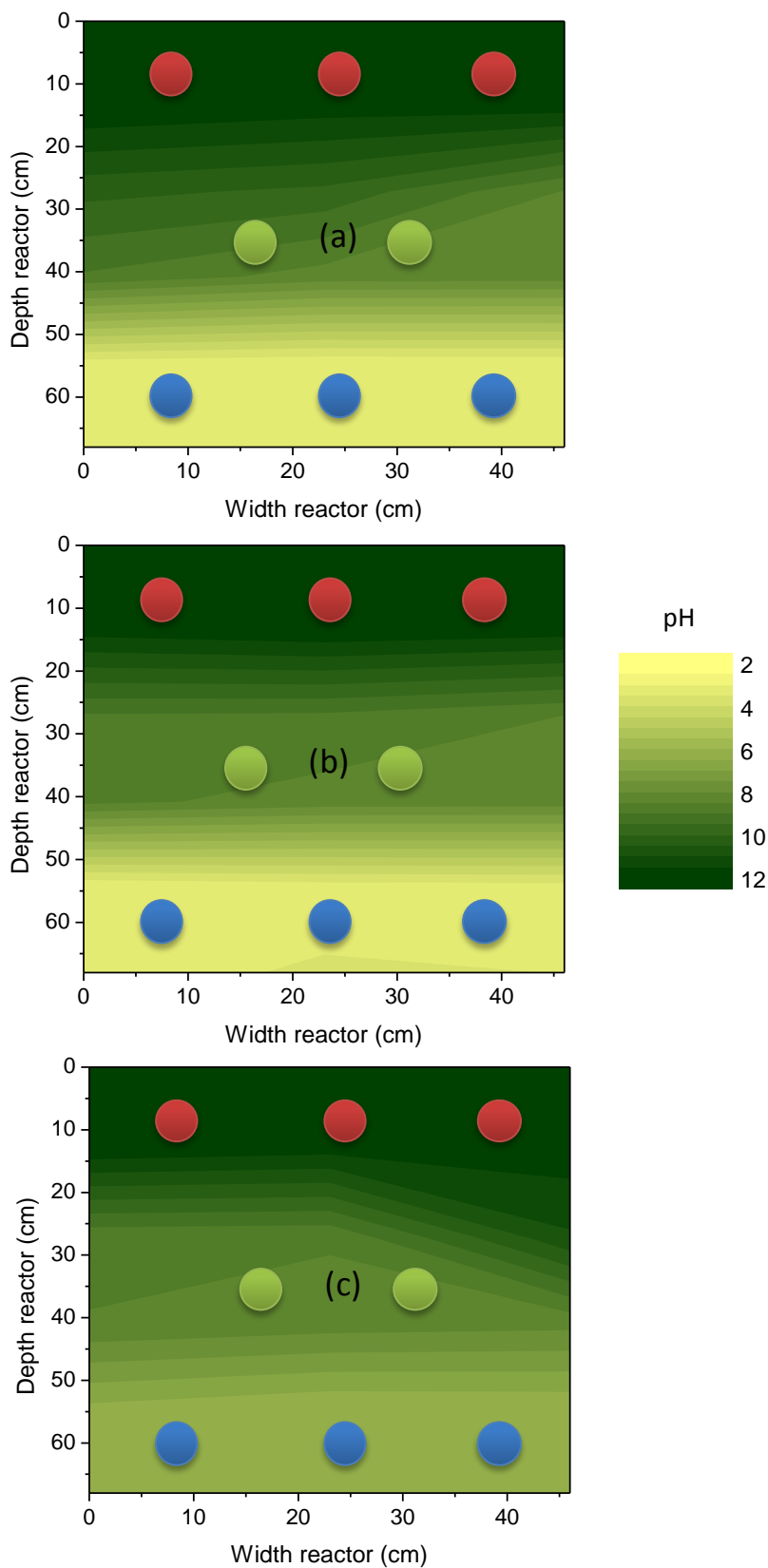

Figure 7. 


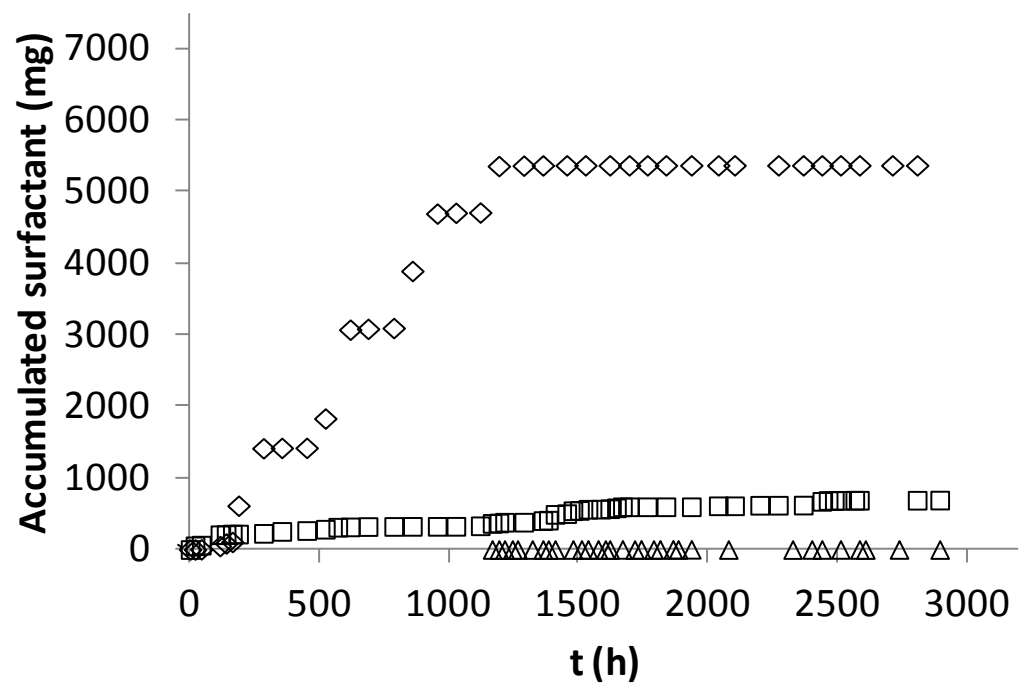

Figure 8. 


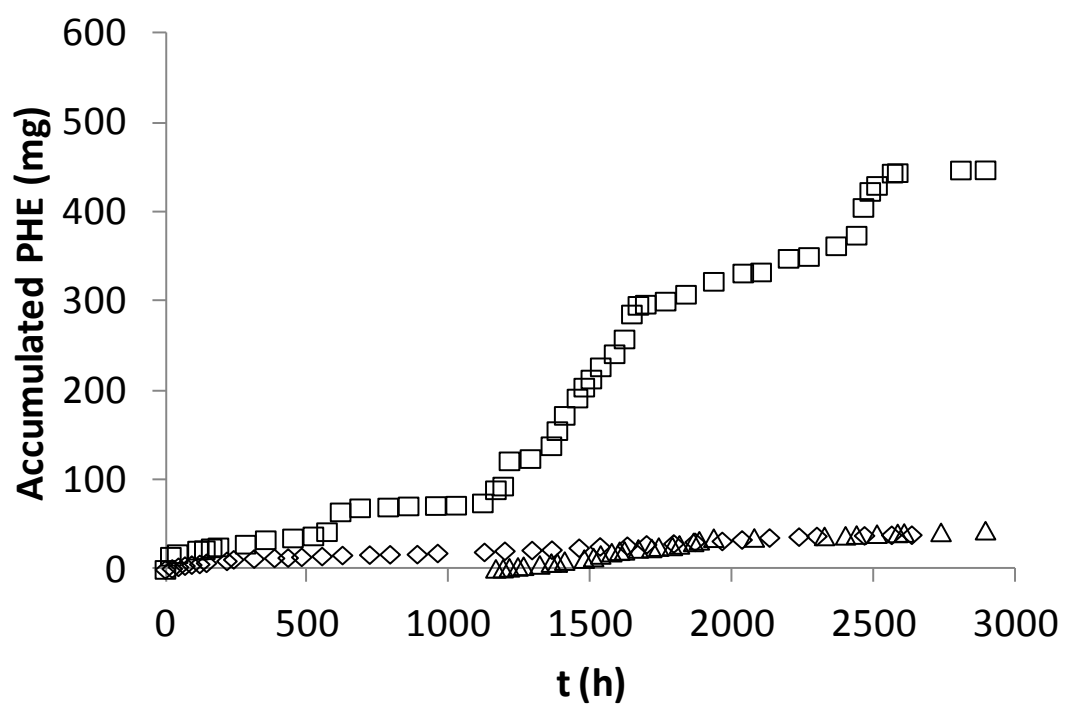

Figure 9. 

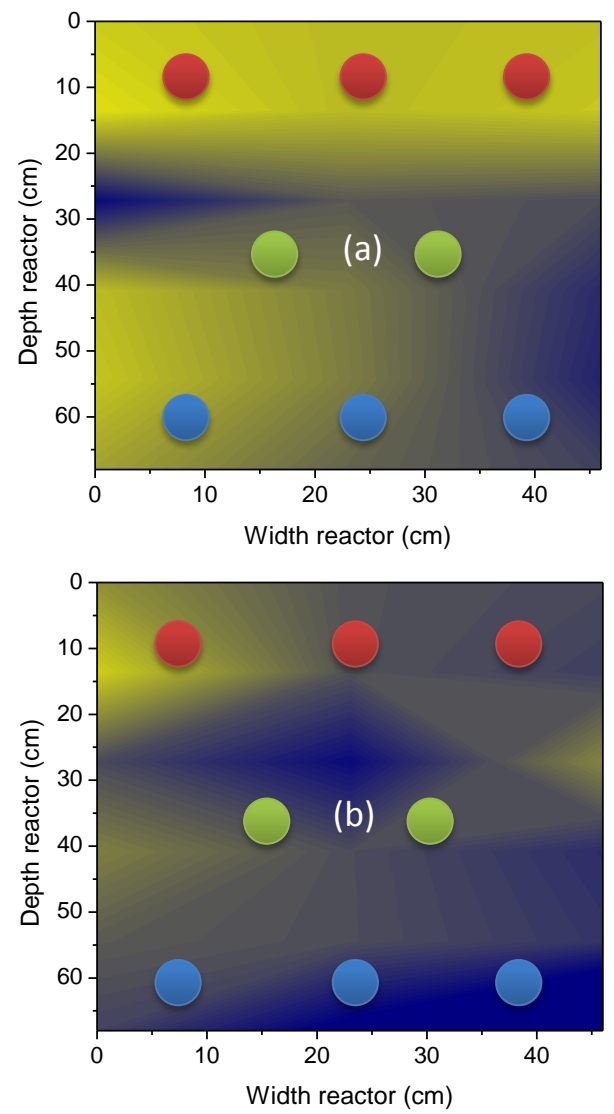

PHE (mg kg-1)


Figure 10. 